\title{
Guia do educador para o filme O Lorax- Em Busca da Trúfula Perdida
}

\author{
Educator's guide to the movie "Dr. Seuss' The Lorax"
}

Lorena Ferrari Uceli PUC Minas Mestre em Entomologia pela Universidade Federal de Viçosa Tutora do curso de Licenciatura em Ciências Biológicas pela UNOPAR, Belo Horizonte, MG, Brasil lorena.uceli@gmail.com Cônia de Araujo
PUC Minas Especialista em Ensino de Ciências e Biologia pela Pontifícia Universidade Católica de Minas
Gerais Apoio de Coordenação pelo ICBS, PUC Minas, em Belo Horizonte, MG, Brasil
kenia@pucminas.br

Marcelo Diniz Monteiro de Barros PUC Minas | Pós-Doutor em Ensino em Biociências e Saúde pelo Instituto Oswaldo Cruz - Fundação Oswaldo Cruz | Coordenador Geral dos cursos de Formação de Professores pela Pontifícia Universidade Católica de Minas Gerais, em Belo Horizonte MG, Brasil marcelodiniz@pucminas.br

\begin{abstract}
Resumo: O Lorax - Em Busca da Trúfula Perdida é um filme norte-americano lançado em 2012, que retrata a aventura de Ted, um jovem habitante de uma cidade futurística inteiramente artificial, na busca de satisfazer o desejo de aniversário do objeto de sua paixão: ver uma árvore de verdade. Em sua trajetória, Ted conhece 'Umavez-ildo', que lhe conta a história da extinção das árvores e a sua experiência com uma criatura fantástica e protetora da natureza, o Lorax. O Guia do Educador elaborado para este filme é um material didático direcionado ao professor de Ciências, a fim de auxiliar o ensino de temas como fotossíntese, ciclos biogeoquímicos, poluição ambiental, efeito estufa, biodiversidade, entre outros. Tem por objetivo auxiliar na diversificação das abordagens educacionais utilizadas em aulas de Ciências, com o intuito de facilitar a aprendizagem sobre temas tão relevantes.
\end{abstract}

Palavras-chave: Ensino de Ciências. Ensino de ecologia. Filme como estratégia pedagógica.

Abstract: "Dr. Seuss' The Lorax" is an American movie released in 2012 which portrays an adventure of Ted, a young inhabitant of an entirely artificial futuristic city, who wants to satisfy his crush's birthday wish: seeing a real tree. In his trajectory, Ted meets 'Once-ler, who tells the story of the extinction of trees and his experience with a fantastic and nature's protector creature, the Lorax. The Educator's Guide prepared for this movie is a didactic material directed to Science teachers, that assist them in the approach of complex subjects such as photosynthesis, biogeochemical cycles, environmental pollution, greenhouse effect, biodiversity, among others. Its objective is to help the diversification of educational approaches in Science classes, in order to facilitate learning about such relevant subjects.

Keywords: Science education. Ecology education. Teaching strategies. Films as pedagogical strategy. 


\section{Introdução}

O ser humano possui diversificadas formas de cognição, logo, diferentes maneiras de aprendizado. Por meio da estratégia de ensino lúdico, obtém-se maior atenção e interesse dos alunos, o que facilita o entendimento do que for abordado (SANTOS \& SILVA 2011; COSTA \& BARROS, 2014). A utilização de mídias audiovisuais em sala de aula, portanto, contribui para a diversificação das aulas e para uma abordagem menos tradicional dos conteúdos a serem trabalhados.

Ao utilizar o filme para um estudo de caso e a partir dele aplicar exercícios que abordem um instrumento de avaliação experiencial, metafórico, de simbolismo, dentre outros, espera-se que o professor consiga resultados melhores do que em aulas essencialmente expositivas (CHAMPOUX, 1999; MENDONÇA \& GUIMARÃES, 2008). Nessa perspectiva, foi elaborado um guia do educador para um filme que aborda conteúdos de Ciências, para que possa ser associado ao ensino dessa disciplina.

Este guia foi pensado para auxiliar na utilização do filme, O Lorax - Em busca da trúfula perdida, como recurso didático em aulas de Ciências, em turmas do Ensino Fundamental II. Segundo Rosa (2000), filmes ou recursos multimídia têm grandes apelos visuais e auxiliam na fixação de conceitos apresentados pelo professor. Além disso, a quebra de ritmo, resultado da aplicação de recursos audiovisuais, é saudável, pois altera a dinâmica e a rotina em sala de aula.

De acordo com a Base Nacional Comum Curricular para o Ensino Fundamental (BNCC, 2017), um dos objetivos do ensino de Ciências é o desenvolvimento do letramento científico nos discentes. Segundo o mesmo documento, letramento científico "envolve a capacidade de compreender e interpretar o mundo (natural, social e tecnológico), mas também de transformá-lo com base nos aportes teóricos e processuais das ciências". Assim, aprender Ciências de forma contextualizada, a fim de desenvolver o senso crítico dos alunos e capacitá-los a atuar no mundo, torna-se mais importante do que memorizar conceitos e compreender fenômenos naturais. Desta forma, o uso de filmes e documentários pode auxiliar o educador na tarefa de contextualizar o conteúdo abordado na disciplina.

O material de trabalho sugerido neste artigo é um filme norte-americano, lançado no ano de 2012, e que conta a história da cidade de Sneedville, um local desprovido de qualquer tipo de vegetação, no qual o ar respirado por seus moradores é comercializado por uma grande empresa. Nessa cidade, vivem Ted e Audrey, dois adolescentes que nunca tiveram contato com nenhuma árvore. Ted, para satisfazer os desejos de Audrey em ver de perto uma trúfula - espécie de árvore 
outrora comum no lugar - sai dos limites da cidade em busca de um espécime. Em sua jornada, encontra-se com Umavez-ildo, um senhor que decide contar a Ted a história da extinção das trúfulas e o seu encontro com uma criatura fantástica e protetora do meio-ambiente, o Lorax.

O objetivo principal deste guia é sugerir uma sequência didática contendo atividades de fácil abordagem e execução, que proporcionem uma melhor compreensão dos alunos acerca de temas apresentados ao longo do filme e que são concernentes à disciplina de Ciências, como fotossíntese, poluição ambiental, ciclos biogeoquímicos, efeito estufa, cadeias e teias alimentares, biodiversidade, consumo e sustentabilidade. Segundo a BNCC (2017), esses conteúdos devem estar inseridos em habilidades educacionais que devem ser desenvolvidas no $7^{\circ}$ ano do Ensino Fundamental II, na Unidade Temática "Vida e Evolução". Sugere-se que o material seja trabalhado em torno de 5 ou 6 aulas, de 50 minutos cada, sendo duas delas geminadas para a exibição do longa-metragem sem interrupção.

Para a condução do debate prévio e realização das atividades posteriores, o professor pode utilizar os roteiros impressos ou escrever as perguntas no quadro para que os alunos copiem, o que for possível, segundo a realidade de cada educador. Os experimentos sugeridos para a aula de número 5 , podem ser realizados em sala, por meio de materiais de fácil acesso à escola e aos alunos.

Todas as atividades aqui propostas podem ser adaptadas de acordo com a realidade das turmas, das escolas e do professor. Este guia é uma sugestão de trabalho, que merece o enriquecimento da experiência do professor que optar por adotá-lo.

\section{Sinopse}

O Lorax (Dr. Seuss' The Lorax, 2012) conta a história de Ted, um habitante de uma cidade distópica isolada do resto do mundo, toda feita de plástico, onde não há árvores, plantas ou animais reais. Certo dia, Ted descobre que o sonho de sua paixão, a bela Audrey, é ver uma árvore de verdade; mais especificamente, uma trúfula - árvore de belo colorido e folhagem macia. Disposto a realizar esse desejo, ele vai atrás de Umavez-ildo, pois, de acordo com a lenda contada por sua avó Norma, é o único capaz de conseguir uma árvore de verdade. O misterioso Umavezildo, que vive para além dos limites da cidade, em um ambiente escuro, inóspito e poluído, insiste em contar a Ted a sua história, relatando como ele, quando jovem, embarcou numa aventura por uma terra desconhecida, cheia de cor, natureza e árvores. Foi lá que ele conheceu o simpático e ao mesmo tempo rabugento Lorax, uma criatura curiosa e fantástica, preocupada com o futuro 
de seu próprio mundo. O contato de Ted com Umavez-ildo e sua história irá alterar a percepção do garoto sobre seu mundo e irá estimulá-lo a tomar atitudes para melhorar o ambiente em que vive.

\section{Público-alvo}

O público-alvo deste guia são alunos do $7^{\circ}$ ano do Ensino Fundamental II. Ele pode ainda ser adaptado para a utilização em outros anos escolares, em aulas de Ciências e Biologia. Temas como consumo (in)consciente, desenvolvimento sustentável e qualidade de vida das populações, também são abordados, o que permite a utilização do material também em práticas interdisciplinares dentro do tema transversal "Meio Ambiente".

\section{Roteiro de atividades}

\section{Primeira aula: avaliação diagnóstica}

Em um momento prévio à exibição do filme, propõe-se uma discussão em sala de aula sobre os principais temas a serem observados na animação, como uma avaliação diagnóstica do conhecimento dos alunos acerca do tema. O professor pode conduzir um debate orientado ou pedir aos alunos que respondam as perguntas em grupo e leiam as suas respostas para a turma ao final da aula, possibilitando uma troca de saberes. Para melhores resultados, recomenda-se o roteiro abaixo:

1. Por que as plantas são importantes para o planeta?

2. Como você relaciona a presença ou a ausência de animais com a quantidade de vegetação em um ambiente? Isto é: se há mais vegetais, há mais ou menos animais? Por que isso ocorre?

3. Qual é a importância das árvores na manutenção do clima de uma região?

4. Qual é a importância das árvores para a qualidade do ar de uma região?

5. O que é poluição?

6. Como a poluição afeta a nossa vida? 
Segunda e terceira aulas: exibição do filme

Em um segundo momento, que seria interessante ocorrer na aula posterior a avaliação diagnóstica, deve acontecer a exibição do filme.

O professor pode introduzir o longa-metragem explicando o tema ou lendo sua sinopse para a turma, relacionando o que os alunos irão assistir à atividade desenvolvida no momento anterior.

O filme tem duração de $1 \mathrm{~h} 26$, portanto é necessário que sua exibição se dê em duas aulas geminadas de, pelo menos, 50 minutos cada, para que não haja uma interrupção da linha de raciocínio do aluno. Se não for possível, o filme pode ser exibido em aulas separadas, sugerindose uma revisão breve da primeira parte antes da exibição da segunda parte.

\section{Quarta aula: estudo dirigido em grupo}

$\mathrm{Na}$ aula seguinte, após a exibição do filme, o professor deverá dividir a turma em grupos de até 4 alunos para que eles respondam às perguntas a seguir. $O$ objetivo desta atividade é avaliar se os alunos compreenderam os conteúdos estudados por eles na disciplina de Ciências que são abordados na animação. Além disso, espera-se que o aluno seja capaz de utilizar os conceitos biológicos e o conhecimento construído ao longo das aulas de Ciências para desenvolver um olhar crítico a respeito dos problemas socioambientais apresentados pelo filme.

1. Descreva, com suas palavras, a cidade de Sneedville: qual a sua aparência? O que há nessa cidade além das pessoas? O que não há na cidade? Como seus habitantes vivem?

2. Por que não há animais de verdade na cidade?

3. As plantas e os animais dependem do oxigênio que existe no ar atmosférico para realizar sua respiração. Sabendo disso, responda:

a) Como é produzido o ar em Sneedville? Ele é pobre ou rico em oxigênio?

b) Como é o ar fora de Sneedville? Por que ele é diferente do encontrado dentro dos muros da cidade?

c) Em determinada cena do filme, o senhor O’Hare diz à Ted “as árvores dão o ar de graça", referindo-se a um processo que acontece nas folhas das árvores, denominado fotossíntese. Esse processo também é citado por Audrey, ao final do filme. Explique o que é a fotossíntese e como ela ocorre.

5. A atmosfera de um local sem nenhuma vegetação tende a ser rica em gás carbônico, um dos responsáveis pelo efeito estufa. Além disso, as árvores produzem sombra e ajudam a 
manter a umidade do ar com a evapotranspiração. Explique como deve ser o clima no lugar onde Umavez-ildo vive.

6. Os sneeds produzidos por Umavez-ildo fizeram sucesso na cidade, todas as pessoas do lugar queriam o seu! Ainda que não soubessem direito para que eles serviam... O que vemos retratado no filme é o chamado "consumismo": um modo de vida em que compramos muitas coisas que nem sempre são, de fato, necessárias. Aponte algumas consequências negativas desse modo de vida.

7. Para produzir seus sneeds, Umavez-ildo precisava das folhas da trúfula. Porém, como vimos no filme, a utilização das árvores de forma predatória, sem preocupação com sua conservação, teve uma consequência ruim, tanto para a natureza quanto para os negócios de Umavez-ildo. Sugira, com seu grupo, uma solução para essa situação em que haja equilíbrio tanto para a manutenção do bosque, quanto para a manutenção da produção de sneeds.

8. “A menos que você não se importe de montão, nada vai melhorar". Essa foi a frase dita a Ted por Umavez-ildo, para que ele modificasse a realidade em que seu mundo se encontrava. Agora, pense na realidade do ambiente em que você vive: sua cidade, seu bairro, o ambiente escolar... Quais problemas ambientais você identifica nestes locais? Como você pode ajudar a resolvê-los?

Respostas sugestivas para o estudo dirigido

1. Resposta pessoal. Espera-se que os alunos notem que a cidade é inteiramente projetada artificialmente, que não possui vegetação e animais reais, sendo os seres humanos os únicos seres vivos a habitarem o local.

2. Para que houvesse animais em Sneedville, seria necessário que também existissem vegetais, uma vez que, em ambientes terrestres, os vegetais são os principais seres fotossintetizantes, produtores de matéria orgânica e energia. Como não há vegetais em Sneedville, também não há herbívoros e, na falta desses, não há seus predadores, dando origem a uma teia alimentar. Portanto, se não existe vegetação não há condições para que populações de animais possam sobreviver nesse ambiente.

3. a) Em Sneedville o ar é puro e rico em oxigênio, porém é purificado artificialmente nas indústrias do Senhor O’Hare e vendido para que a população da cidade possa consumi-lo.

b) Fora de Sneedville o ar é poluído e pobre em oxigênio. 
4. A fotossíntese é um processo de produção de alimento (como a glicose), realizado por organismos clorofilados como as plantas e algas do fitoplâncton. "Nesse processo, o organismo utiliza três fatores do ambiente: a luz solar, o gás carbônico e a água, produzindo glicose e gás oxigênio" (JÚNIOR et al, 2011). Nas plantas terrestres, a água é retirada do solo por meio das raízes e levada até as folhas e outras partes verdes da planta, ricas em clorofila, pigmento verde responsável por absorver a luz do sol.

O gás carbônico é absorvido do ar atmosférico por estruturas presentes na face inferior da folha, denominadas estômatos. Na presença de luz, a água e o gás carbônico sofrem uma reação química que dá origem à glicose, que será utilizada pela planta para a produção de energia por meio da respiração celular (seu excesso é armazenado em formato de amido), e ao oxigênio, liberado na atmosfera.

5. O clima no ambiente onde Umavez-ildo vive deve ser quente, já que o ar daquele ambiente é poluído por todos os gases produzidos pela cidade de Sneedville e pelas indústrias do senhor O’Hare. Como não há vegetação, a atmosfera é rica em gás carbônico, um dos principais causadores do aumento da temperatura do planeta, por meio do agravamento do efeito estufa. $\mathrm{O}$ clima também deve ser seco, pois a vegetação ajuda a manter a umidade do ar e o regime de chuvas, uma vez que a água evaporada no continente provém muito mais da transpiração dos vegetais do que da evaporação de rios e lagos (JÚNIOR et al, 2011).

6. Algumas consequências negativas de um modo de vida consumista são a grande produção de resíduos sólidos, exploração dos recursos naturais de forma predatória (desmatamento, mineração etc.), poluição atmosférica e hídrica pelas indústrias de bens de consumo, extinção de espécies, supervalorização dos bens materiais e desvalorização das relações humanas e dos seres humanos com o ambiente, etc.

7. Para que houvesse equilíbrio ambiental e econômico, Umavez-ildo poderia ter investido em reflorestamento e replantio das árvores de trúfula que ele utilizava em sua produção de sneeds. Concomitantemente, poderia ter reservado uma área para plantio de trúfulas que seriam direcionadas apenas à produção de sneeds, para que, no futuro, não houvesse necessidade de desmatar o bosque para a utilização das plantas. Além dessas medidas, Umavez-ildo poderia ter desenvolvido uma técnica que retirasse apenas algumas folhas de cada árvore por vez, permitindo que as plantas permanecessem vivas e possibilitando a renovação das folhas. Enfim, todas as respostas se relacionam ao conceito de desenvolvimento sustentável, que, segundo o relatório final da Comissão Mundial para o Meio Ambiente e o Desenvolvimento (1988), "é aquele que 
atende as necessidades do presente sem comprometer as possibilidades de as gerações futuras atenderem suas próprias necessidades".

8. Resposta pessoal. Espera-se que os alunos utilizem os conceitos vistos nas aulas de Ciências e que foram reforçados na atividade para elaborarem suas respostas.

\section{Quinta aula: atividade prática}

Esta atividade está sendo proposta para a quinta aula, mas pode ser utilizada também como atividade diagnóstica, anterior à exibição do filme, caso o professor assim decida.

A seguir, são indicados dois experimentos para a fixação de alguns conceitos. Um dos experimentos tem como objetivo evidenciar a fotossíntese em uma planta aquática e o segundo experimento permite reproduzir as consequências do efeito estufa.

As atividades práticas possuem grande importância quando usadas como complementação às aulas teóricas e a outras abordagens educacionais, possibilitando ao aluno relembrar conceitos, confirmar fatos científicos estudados em teoria, o que contribui para a aprendizagem significativa (ARAÚJO \& ABIB, 2003).

Experimento 1 - Fotossintese em plantas aquáticas

\section{Materiais}

- 02 garrafas PET transparentes de 500mL ou 1L;

- Ramos de Elodea sp;

- Bicarbonato de sódio

- Papel alumínio;

- 02 luminárias com lâmpadas incandescentes;

- Água.

\section{Procedimentos}

Peça aos alunos que enumerem as garrafas PET com '1' e '2'. Na garrafa de número 1, os alunos acrescentarão água e adicionarão uma colher de sobremesa de bicarbonato de sódio, agitando bem a água para que o bicarbonato se dissolva. 
Posteriormente, colocarão um ou dois ramos de Elodea sp. dentro da garrafa e a tamparão. O mesmo procedimento deve ser realizado na garrafa de número 2, que deverá ser completamente envolta, posteriormente, com o papel alumínio, a fim de impedir a passagem de luz.

Ambas as garrafas deverão ser expostas ao sol. Caso não haja sol intenso no momento da aula, o experimento pode ser feito utilizando-se duas luminárias com lâmpadas incandescentes em cada uma delas. Nesse momento, é importante que o professor questione os alunos sobre o que eles imaginam que irá acontecer em cada uma das garrafas e peça para que eles anotem suas hipóteses.

Após 30 minutos, observarão o resultado obtido em cada uma das garrafas. O professor discutirá o resultado com os alunos, podendo ser utilizado o roteiro a seguir como norteador:

1. O que aconteceu na garrafa 1 ? E na garrafa 2 ? Por quê?

2. Por que adicionamos bicarbonato de sódio na água dentro das garrafas? Que elemento presente no bicarbonato é importante para a realização do fenômeno observado?

3. O que são as bolhas que observamos na garrafa 1 ?

4. Que elemento estava ausente na reação da garrafa 2 , que impediu a formação de bolhas? Explique a importância deste elemento para o fenômeno estudado.

Experimento 2 - Simulador do Efeito Estufa

\section{Materiais}

- 02 copos com água;

- Papel alumínio;

- 01 caixa de sapato;

- Tesoura;

- Filme plástico;

- Luminária com lâmpada incandescente;

- Termômetro químico (opcional). 
Procedimentos

Esta atividade pode ser feita simultaneamente por vários grupos de alunos, cada um com seu conjunto de materiais. Com o auxílio do professor, os alunos deverão forrar o interior da caixa de sapatos com o papel alumínio. Colocarão um dos copos contendo água no interior da caixa e a cobrirão com o filme plástico.

Os alunos, então, irão dispor a caixa e o copo d'água sobressalente sob o sol ou debaixo de uma luminária com lâmpada incandescente acesa. Neste momento, o professor pode pedir aos alunos para formularem hipóteses sobre o que acontecerá com a água de cada copo e o porquê, e anotá-las em seus cadernos.

Após 15 minutos de exposição à luz, os alunos abrirão a caixa e experimentarão a temperatura da água nos dois copos com o dedo indicador. Nesta etapa, um termômetro químico pode ser utilizado para medir as temperaturas em cada um dos copos.

Ao final da experimentação, o professor conduzirá um debate a respeito dos resultados, podendo seguir o roteiro de perguntas proposto a seguir:

1. Em qual dos copos a temperatura estava mais alta?

2. Como você explica esse resultado?

3. O que é o efeito estufa e como ele se relaciona ao experimento que realizamos?

4. O efeito estufa é um fenômeno natural ou artificial?

5. Quais gases estão relacionados à sua intensificação?

6. Que impactos ambientais são causados pelo aumento do efeito estufa?

\section{$7 \mathrm{O}$ que podemos fazer para amenizar esses impactos?}

\section{Atividade complementar - Bônus}

Esta atividade serve como complementação do trabalho, por isso, não é sugerido um momento específico para desenvolvê-la, assim, o professor pode realizá-la quando achar oportuno. É uma atividade que envolve o uso de palavras-cruzadas, com a ideia de trabalhar, também, os jogos em sala de aula.

Segundo Benedetti Filho et al (2009), o uso do lúdico em sala de aula pode ser uma ferramenta que desperta o interesse da maioria dos alunos, motivando-os a buscar soluções e 
alternativas que resolvam e expliquem as atividades propostas. Sendo assim, a atividade desenvolvida é apresentada abaixo:

Figura 1: Palavras-Cruzadas - https://www.educolorir.com/crosswordgenerator/por/index.html

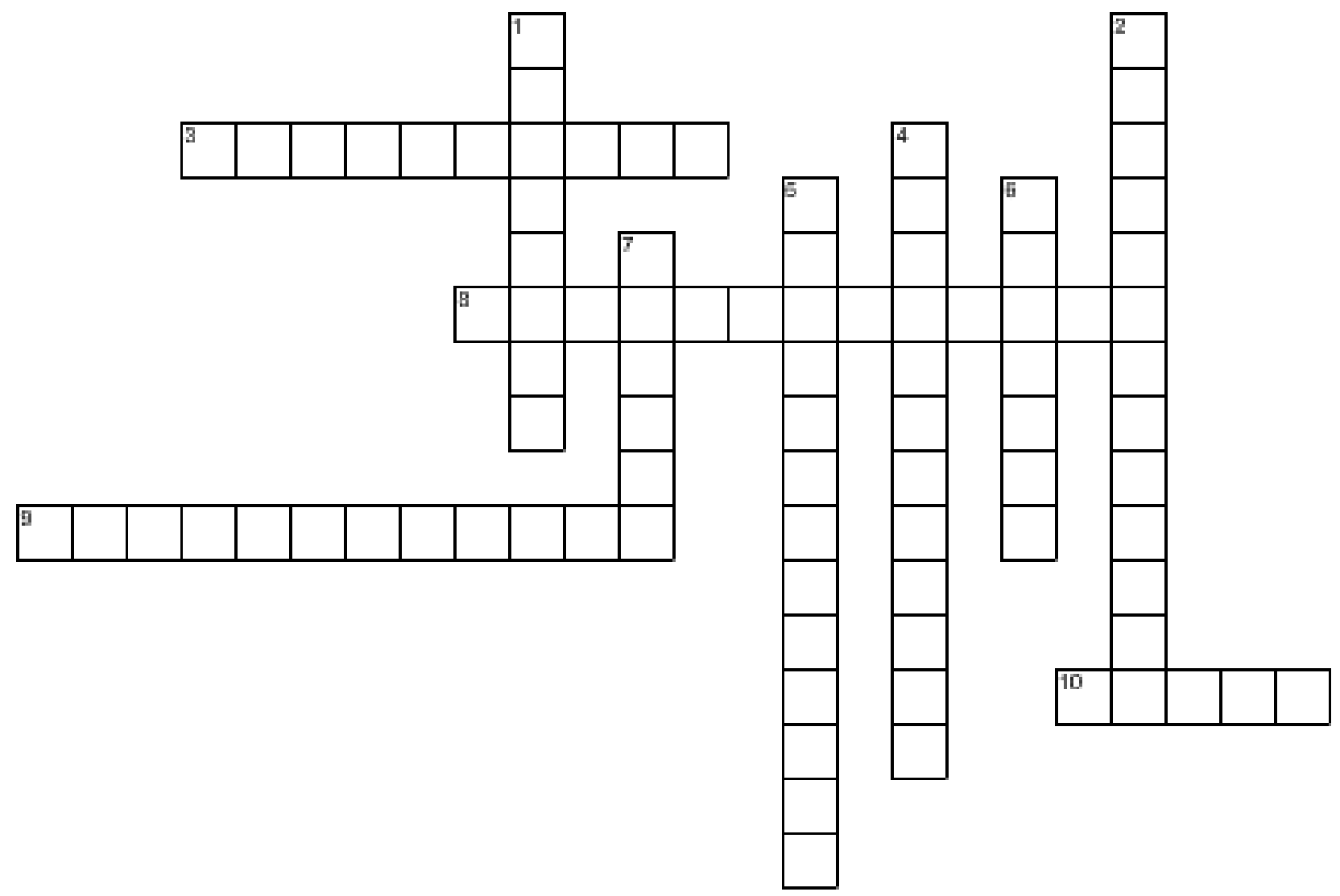

Horizontais:

3. Utilização desenfreada dos sneeds.

8. Tipo de radiação que mantêm nosso planeta aquecido.

9. Processo realizado pelas plantas para a produção de energia necessária aos seres vivos.

10. Criatura curiosa e fantástica, preocupada com o futuro de seu próprio mundo.

\section{Verticais:}

1. Gás indispensável à vida dos seres humanos, animais e plantas.

2. Um dos gases responsáveis pelo aumento do efeito estufa.

4. Umavez-ildo cortou todas as árvores disponíveis. Como denominamos o que ele fez? 
5. Fenômeno que mantém nosso planeta aquecido.

6. Situação em que o ambiente no qual Umavez-ildo vive se encontra.

7. O que Audrey sonhava em ver de verdade.

Respostas: 1.Oxigênio, 2. Gás-carbônico, 3. Consumismo, 4. Desmatamento, 5. Efeito-estufa, 6. Poluído, 7. Árvore, 8. Infravermelha, 9. Fotossíntese, 10. Lorax.

\section{Considerações finais}

Acreditamos que as sugestões apresentadas neste guia do educador serão de grande auxílio no processo de ensino-aprendizagem dos alunos do Ensino Fundamental II. Conforme citado, a utilização de metodologias que envolvam o lúdico ajuda a despertara atenção e o interesse dos alunos, sendo uma alternativa eficaz às aulas expositivas convencionais. A utilização do filme apresentado neste trabalho, seguido das atividades propostas, confere ao professor ou professora de Ciências uma ferramenta interessante na abordagem de conceitos e conteúdos de relativa complexidade. Esperamos que o material aqui proposto estimule os docentes da área a diversificarem suas práticas, percebendo que é possível usar de novas metodologias para alcançar os objetivos pedagógicos pretendidos.

\section{Referências}

ARAÚJO, M. S. T; ABIB, M. L. V. S. Atividades Experimentais no Ensino de Física: diferentes enfoques, diferentes finalidades. Revista Brasileira de Ensino de Física, v.25, n.2, p.176-194, 2003.

BENEDETTI FILHO, E.; FIORUCCI, A. R.; BENEDETTI, L. P. S.; CRAVEIRO, J. A. Palavras Cruzadas como Recurso Didático no Ensino de Teoria Atômica. Química Nova na Escola, V.31, n.2, p.88-92, 2009.

BRASIL. Ministério da Educação e Cultura. Base Nacional Comum Curricular. Brasília: MEC, 2017.

CHAMPOUX. J. E. Film as a teaching resource. Journal of Management Inquiry, v.B, n.2, p.206 - 217, 1999.

CMMAD - Comissão Mundial sobre Meio Ambiente e Desenvolvimento. Nosso futuro comum. 2a ed. Tradução de Our common future. 1a ed. 1988. Rio de Janeiro: Editorada Fundação Getúlio Vargas, 1991. 


\section{Dialogia}

COSTA, E. C. P.; BARROS, M. D. M. Lu₹z câmera, ação: o uso de filmes como estratégia para o ensino de Ciências e Biologia. Revista Práxis, V.6, n.11, p.81-93, 2014.

MENDONÇA, J. Ricardo de C., GUIMARÃES, Flávia Peixoto. Do quadro aos "quadros": o uso de filmes como recurso didático no ensino de administração. Cadernos EBAPE.BR [em linha] 2008, (AgostoSem mês): Disponível em:<http://www.redalyc.org/articulo.oa?id=323228071003> ISSN. Acesso em: 5 out. 2017

JÚNIOR, C. S.; SASSON, S.; JÚNIOR, N. C. Biologia: Volume Único. $5^{\text {a }}$ ed. São Paulo: Saraiva, 2011.

ROSA, P. R. S. O uso dos recursos audiovisuais e o ensino de Ciências. Caderno Catarinense de Ensino de Física, v.17, n.1, p.33-49, 2000.

SANTOS, C.R.M.; SILVA, P.R.Q. A utilização do lúdico para a aprendiragem do conteúdo de genética. Universitas Humanas, v. 8, n. 2, p. 119-144, 2011.

Recebido em: 30 maio 2019 / Aprovado em: 21 nov. 2019

\section{$\underline{\text { Cite como }}$}

UCELI, Lorena Ferrari; ARAUJO, Kênia de; BARROS, Marcelo Diniz Monteiro de. Guia do Educador para o Filme O Lorax- Em Busca da Trúfula Perdida.Dialogia, São Paulo, n. 33, p. 205217, set./dez. 2019. Disponível em: https://doi.org/10.5585/Dialogia.n33.14529. 